\title{
AVALIAÇÃO DO POTENCIAL DA INTERFEROMETRIA SAR PARA O MAPEAMENTO ALTIMÉTRICO DE ÁREAS REFLORESTADAS POR EUCALYPTUS SP.
}

An evaluation of interferometric SAR potential for altimetric mapping of reforested áreas by eucalyptus $S P$

\author{
FÁBIO FURLAN GAMA \\ JOSÉ CLAUDIO MURA \\ PAULO CÉSAR GURGEL DE ALBUQUERQUE \\ JOÃO ROBERTO DOS SANTOS
}

\author{
Instituto Nacional de Pesquisas Espaciais \\ Av. dos Astronautas 1758 São José dos Campos - SP - Brasil \\ CEP: 12.227- 010, Fax: (12) 32086468
}

fabio@dpi.inpe.br; mura@dpi.inpe.br; gurgel@dsr.inpe.br; jroberto@dsr.inpe.br

\begin{abstract}
RESUMO
Este trabalho tem como objetivo avaliar a qualidade altimétrica dos modelos de elevação (MDE) gerados através da interferometria SAR (Synthetic Aperture Radar) nas bandas X e P, em diferentes polarizações em áreas florestadas. Este estudo foi realizado no município de Pindamonhangaba/SP, em uma área caracterizada por reflorestamento de Eucalyptus saligna de 6 anos de idade, cujo inventario florestal e levantamento topográfico foram realizados no mesmo período do aerolevantamento. Verificou-se que nesta área florestada o modelo de elevação da superfície do dossel empregando a interferometria na banda $\mathrm{X}$, gerou produtos cartográficos de precisão inferior a esperada, com desvio padrão na ordem 2,7 metros. A utilização de um modelo de regressão, que combinou a coerência interferométrica e o MDE, compensou os erros de medida da altura da vegetação, melhorando a qualidade do produto cartográfico para desvio padrão da ordem de 1,4 metro atingindo a resolução altimétrica desejada. Os modelos de elevação do terreno na banda $\mathrm{P}$, polarização $\mathrm{HH}$, em áreas florestadas apresentaram similaridade com os dados do levantamento topográfico, com desvio padrão na ordem de 1,97 metro, devido à maior penetração do feixe do radar na floresta de Eucalyptus e conseqüentemente uma maior interação com o solo do que com as árvores. O
\end{abstract}


modelo de elevação do solo na banda $\mathrm{X}$ em áreas de pasto apresentou um desvio padrão de 0,6 metro, cuja escala de mapeamento foi compatível com a resolução empregada, enquanto que os modelos de elevação na banda $\mathrm{P}$ apresentaram um valor de desvio padrão de 6 a 20 metros conforme a polarização, devido ao espalhamento especular, causando uma baixa relação sinal/ruído.

Palavras-chave: SAR; interferometria; Eucalyptus; MDE.

\section{ABSTRACT}

This study aims at assessing the quality of the altimetric elevation models (DEM) generated by interferometric SAR (Synthetic Aperture Radar) bands X and P in different polarizations for forested areas. This study was carried out in Pindamonhangaba/SP region, in an area featured by a 6 year old Eucalyptus saligna reforestation, whose forest inventory and topographic survey were conducted in the same air-surveying period. It was found out that canopy DEM using interferometry in the X-band was less precise than expected, with 2.7 meter standard deviation. By using a regression model that combined interferometric coherence and DEM, made up for the vegetation height measurement errors improved the quality of the cartographic product for standard deviation about 1.4 meters, reaching the desired resolution. The ground elevation models in $\mathrm{P}$ band, $\mathrm{HH}$ polarization, for forested areas showed similarity to the surveyed topographic data, with a standard deviation of around 1.97 meters, due to a greater radar beam penetration at Eucalyptus forest and therefore a greater interaction with the soil than that of with the trees. The DEM in X-band for pasture areas had a 0.6 meter standard deviation, and the mapping scale was compatible with the resolution, whereas elevation model in P-band showed a standard deviation value in the order of 6 to 20 meters, according to polarization, due to the specular scattering causing a low signal/noise ratio.

Keywords: SAR; interferometry; Eucalyptus; DEM.

\section{INTRODUÇÃO}

A técnica da interferometria utilizando radares de abertura sintética (SAR, Synthetic Aperture Radar, Radar de Abertura Sintética) consiste basicamente em utilizar um radar imageador, empregando um par de antenas para o imageamento, separadas fisicamente no espaço por uma distância conveniente, denominada linhabase ou baseline (Graham, 1974), obtendo assim duas imagens do mesmo alvo em visadas ligeiramente diferentes.

Os pixels destas duas imagens são representados no formato complexo, ou seja, possuem amplitude e fase. Combinando as duas imagens através da multiplicação dos pixels homólogos, um pelo complexo conjugado do outro, obtémse a diferença de fase entre os pixels, que está relacionada com a elevação do terreno correspondente à célula de resolução no solo, possibilitando com isso a geração de um Modelo Digital de Elevação (MDE), (Mura, 1993).

Segundo Zebker e Villasenor (1992), um fator a ser considerado para a 
qualidade dos dados interferométricos é o grau de correlação complexa entre os pixels homólogos das imagens, cujo módulo é denominado de coerência interferométrica (coherence), que apresenta uma relação direta com a precisão do MDE por interferometria. Os autores verificaram que, nos casos de interferometria de duas passagens, especialmente o satélite Seasat - banda L, a coerência diminui significativamente para áreas vegetadas à medida que as passagens do satélite eram mais espaçadas no tempo, devido à diferença de posição das folhas e galhos, enquanto que para áreas de solo exposto a coerência interferométrica não apresentou nenhuma alteração temporal.

Segundo Borgeaud e Wegmueller (1996), em áreas florestadas a coerência interferométrica pode variar com o incremento da biomassa da vegetação, com os efeitos do terreno, e com as mudanças das constantes dielétricas (alagamento, umidade, congelamento), e com a freqüência de operação do radar.

Mura et al. (2001) utilizaram dados interferométricos obtidos na Floresta Nacional do Tapajós- PA, nas bandas de operação X e P, observaram que a diferença entre os MDEs na banda $P$, de alta penetração no dossel, e na banda $X$, de baixa penetração, poderia obter a altura interferométrica (Hint) referente a altura da vegetação.

Neeff et al. (2005) combinaram a técnica descrita por Mura et al. (2001), e a radiometria da banda $\mathrm{P}_{\mathrm{HH}}$, para determinar a biomassa da vegetação, sem observar o efeito da saturação de estimativa, que ocorre normalmente quando se utiliza somente a resposta radiometrica do radar.

Gama et al.(2006) realizaram, em cooperação com as empresas Orbisat Aerolevantamentos S.A. e Nobrecel Celulose e Papel S.A., uma campanha empregando um radar tipo SAR aerotransportado multipolarizado $(\mathrm{HH}, \mathrm{HV}, \mathrm{VH}$, $\mathrm{VV})$ na banda $\mathrm{P}(\lambda=72 \mathrm{~cm})$, e na banda $\mathrm{X}(\lambda=3 \mathrm{~cm})$ numa área de reflorestamento de Eucalyptus, no Vale do Paraíba (Estado de São Paulo), com o objetivo de obter um melhor entendimento da interação do sinal de microondas com os parâmetros estruturais do povoamento, e desenvolver modelos de estimativa da altura, DAP e volume utilizando a polarimetria e interferometria SAR.

A partir dos dados de campo obtidas nesta campanha, foi realizado um estudo de avaliação da qualidade dos diferentes MDEs gerados pelo radar interferométrico OrbiSAR-1, nas bandas X e P, em áreas reflorestadas com Eucalyptus, que é o objetivo deste trabalho.

\section{2. ÁREA DE ESTUDO}

Para o desenvolvimento deste trabalho foi selecionada uma área de reflorestamento da empresa de celulose Nobrecel S/A, localizada no município de Pindamonhangaba/SP, composta por talhões de Eucalyptus em duas idades de plantio. A Figura 1 apresenta uma imagem de radar na banda $\mathrm{X}$, obtida pela empresa Orbisat em dezembro de 2004. 
Fig. 1 - Imagem da banda X com a posição dos transectos.

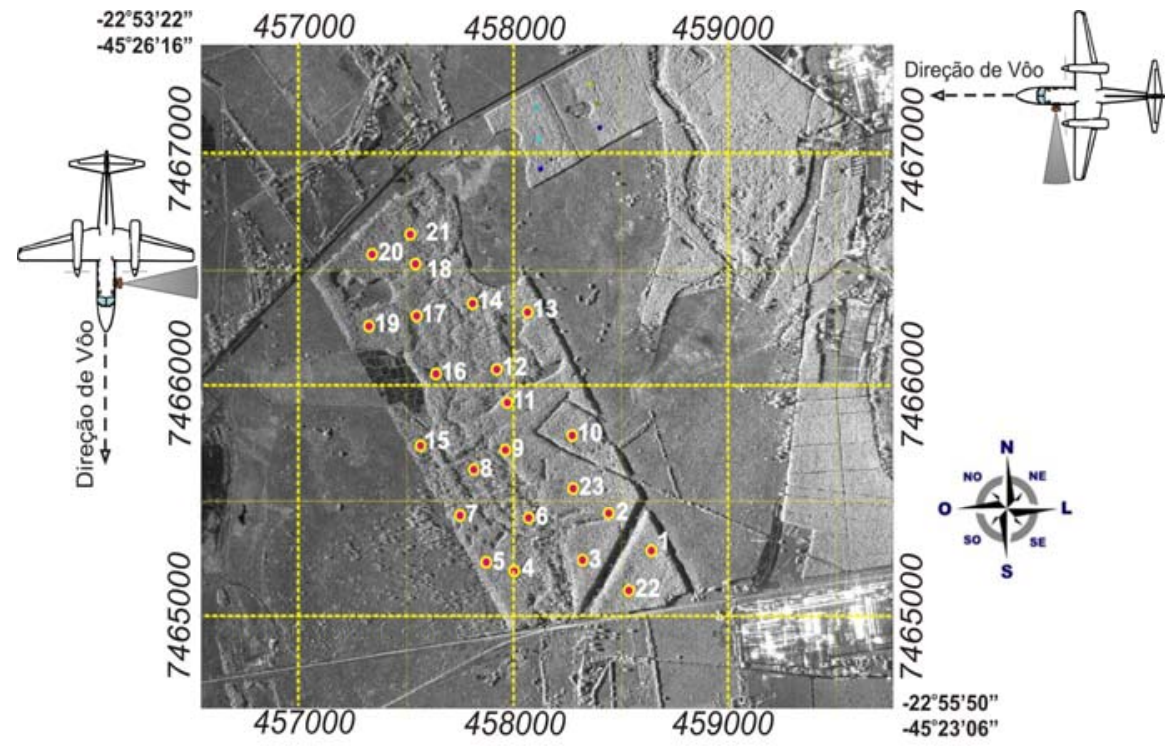

A área de estudo era composta por uma plantação de Eucalyptus saligna, com espaçamento de 3 x 2 metros, de 6 anos de idade, com uma altura média de 23,33 metros, cujo plantio recobre uma área total de 128,64 hectares, com a finalidade a produção de celulose. A área de estudo possui também uma região denominada Coruputuba, composta de povoamentos clonais de híbridos de Eucalyptus Grandis e Eucalyptus Urophylla, com espaçamento de $3 \times 2$ metros, denominados clones Rosa e Branco, com idade de 2,3 anos, com uma altura média de 14,83 metros e uma área plantada de 16,38 hectares. A região de estudo é composta por dois platôs com uma diferença altimétrica de aproximadamente 10 metros entre si.

As áreas reflorestadas eram circundadas por áreas de pasto, que foram utilizadas como áreas de referência para o estudo do efeito da cobertura florestal nos modelos de elevação do terreno.

A altitude da área varia entre 530 a 560 metros, e o clima dominante da região é do tipo Cwa de acordo com a classificação de Koeppen, ou seja, úmido, com temperaturas quentes no verão e inverno ameno. No verão as chuvas são quase diárias e normalmente o total mensal excede $200 \mathrm{~mm}$, com um total médio anual de 1335 mm (Köppen, 1948).

O solo da região de estudo é enquadrado como do tipo LA6, distróficos latossólicos argilossolos vermelho-amarelo, com relevo suave ondulado e plano, segundo o mapa pedológico do Estado de São Paulo de 1999 (Oliveira et. al., 1999). 


\section{MATERIAIS E METODOS}

\subsection{Metodologia empregada}

Para o desenvolvimento desse estudo foram empregados dados de radar interferométrico e polarimétrico, levantamento topográfico nas áreas de floresta em associação com o respectivo inventário florestal das parcelas, para determinar as relações entre os parâmetros inventariados e os valores de altimetria nas diferentes polarizações, obtidas pelo sistema radar. No inventário florestal realizaram-se medidas amostrais dos parâmetros dendrométricos: altura total e comercial das árvores e as falhas do povoamento.

Para a obtenção dos dados de radar empregou-se o radar imageador aerotransportado de abertura sintética interferométrico OrbiSAR-1, da empresa Orbisat, que opera nas quatro polarizações na banda $\mathrm{P}$ e na polarização $\mathrm{HH}$ para a banda X.

A obtenção das imagens pelo radar foi realizada em 14 de dezembro de 2004, às 02:00h, não havendo precipitação na região nas 32 horas que antecederam ao sobrevôo, conforme os dados obtidos no sítio do CPTEC (Centro de Previsão de Tempo e Estudos Climáticos) referente à estação meteorológica 32663 do município de Pindamonhangaba.

A escala usada no imageamento foi de 1:25000 para a banda P e 1:10000 para a banda $\mathrm{X}$, que corresponderam aos melhores escalas de mapeamento que o radar OrbiSAR-1 dispunha. Para este mapeamento foram realizados vôos cruzados para minimizar o efeito de sombra e de regiões de baixa coerência nas florestas de Eucalyptus. As etapas de trabalho foram executadas segundo o diagrama apresentado na Figura 2.

Fig. 2 - Procedimento metodológico.

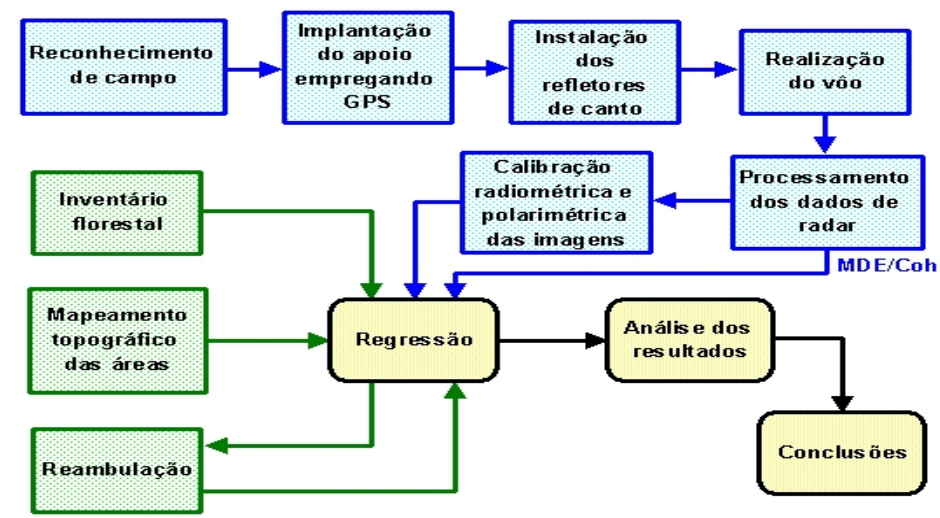

\subsubsection{Sinalização para o imageamento}

Bol. Ciênc. Geod., sec. Artigos, Curitiba, v. 16, nº 4, p.519-537, out-dez, 2010. 
A primeira etapa realizada do trabalho foi o reconhecimento de campo, que basicamente consistiu da avaliação das áreas de instalação dos sinalizadores.

Para a realização do aerolevantamento radargramétrico, foi necessária uma sinalização prévia por meio de sinalizadores metálicos (refletores de canto ou corners reflectors), formado por três superfícies planas triangulares com 2 metros do seu lado maior, mutuamente perpendiculares com a finalidade de refletir as ondas eletromagnéticas em direção a fonte.

As respostas destes refletores possibilitaram a calibração de fase para o processamento interferométrico, além de servir como pontos de controle para a geração dos MDEs. A resposta radiométrica dos refletores de canto foi utilizada como referência para a calibração radiométrica e polarimétrica das imagens.

Os pontos assinalados em vermelho da Figura 1 indicam os locais onde os refletores foram instalados, cujo apontamento para a aeronave foi realizado através da orientação dos ângulos de elevação e azimute a partir de um planejamento prévio das faixas de vôo, conforme ilustrado nas Figuras 3a e 3b.

Fig. 3 - Orientação dos corners reflectors: a) em elevação; b) em azimute.

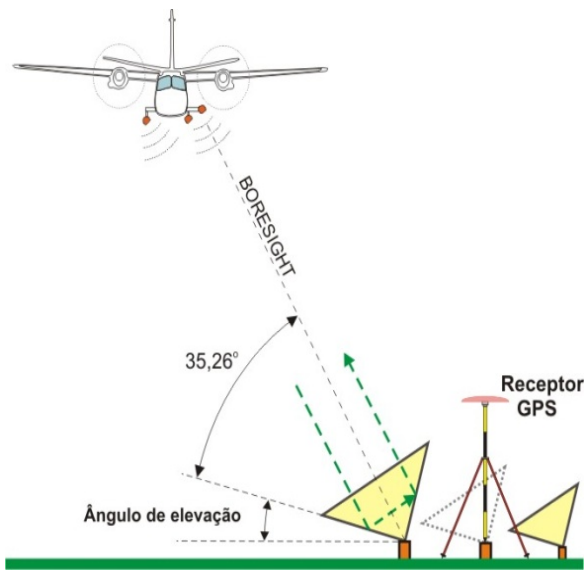

a)

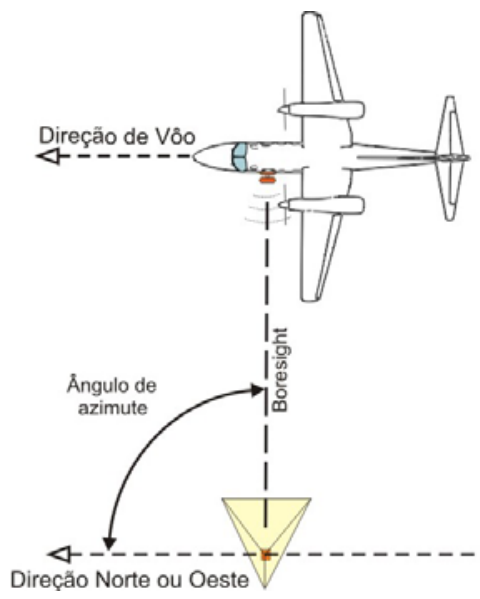

b)

Para a instalação destes sinalizadores, foi necessária a "implantação do apoio" que consistiu na materialização desses pontos e a determinação de suas coordenadas por meio do sistema de posicionamento global (GPS-Geodésico), método estático relativo, e empregando a constelação GPS disponível na época.

A precisão plano-altimétrica obtida por ajustamento para o posicionamento dos refletores foi de aproximadamente 5,0 centímetros, e como referência foi empregado o DATUM WGS-84, que é praticamente igual ao SIRGAS2000. Estes pontos de apoio foram implantados em clareiras próximas às áreas de 
reflorestamento, de forma a permitir a visibilidade do refletor pelo radar, evitando que algum objeto próximo ao refletor interferisse na calibração radiométrica e interferométrica. A Figura $4 \mathrm{~b}$ apresenta a foto de um dos oito refletores de canto que foram instalados nas áreas de pasto no entorno da área de estudo.

Fig. 4 -a) - Base SGB SAT - 91537; b) - Foto de um refletor de canto instalado na

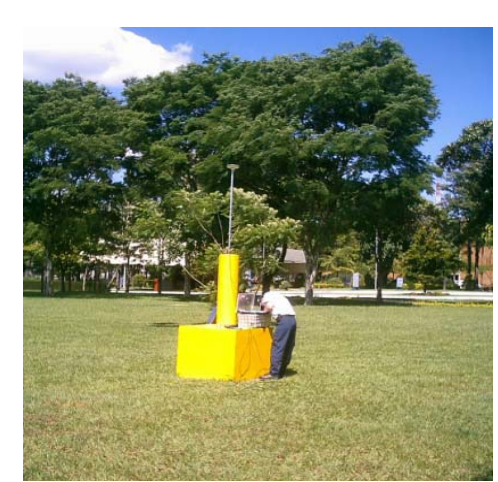

a)

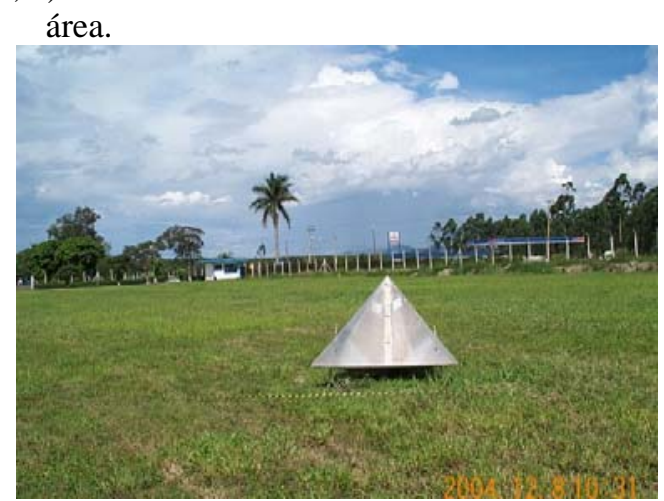

b)

Além dos pontos de apoio implantados, foi necessária a instalação de um ponto de referência com coordenadas geográficas conhecidas no aeródromo de São José dos Campos, local de operação da aeronave, para ajuste e calibração da unidade IMU (Inertial Moviment Unit) embarcada.

A IMU é basicamente composta de uma plataforma inercial associada a um GPS aeronáutico de navegação, que permitiu obter as medidas de atitude da aeronave ("vetor de atitude") com a precisão necessária para realizar as devidas compensações do movimento da aeronave. A Figura 4a apresenta a base do IBGE SAT-91537, utilizada como base para o rastreio do ponto do aeródromo de São José dos Campos.

Após a aquisição dos dados brutos do radar interferométrico, eles foram processados para obter as imagens SAR polarimétricas, os MDEs por interferometria e a coerência interferométrica.

\subsubsection{Levantamento topográfico}

O levantamento topográfico consistiu das medidas de elevação do terreno sob o reflorestamento e em parte da área de pasto, empregando estação total e GPS geodésico.

Medições topográficas também foram realizadas após o vôo nas parcelas inventariadas para a verificação da penetração do sinal do radar em banda $\mathrm{P}$, empregando um espaçamento entre as medidas de aproximadamente 10 metros, tanto no sentido longitudinal quanto no sentido ortogonal, de forma a obter um 
modelo topográfico compatível com o modelo de elevação interferométrico.

Para a execução do levantamento topográfico foi utilizada uma estação total marca Topcon, modelo GTS - 701, com dois prismas, com visadas vante e ré para medição das respectivas distâncias, permitindo aferir a qualidade das medidas topográficas mantendo os erros plani-altimétricos inferiores a $5,0 \mathrm{~cm}$ no pósprocessamento. Foram realizadas 106 medidas em áreas de pasto e 1221 medidas no interior do povoamento de Eucalyptus.

Os pontos de partida do levantamento topográfico corresponderam a dois pontos de sinalização implantados durante o levantamento com GPS, para colocação de refletores de canto. Partiu-se desta forma, de áreas abertas para o interior do reflorestamento realizando uma poligonal fechada, e a partir desta poligonal foram realizados levantamentos por irradiamento para o interior das parcelas. A Figura 5a apresenta o trabalho de levantamento topográfico no interior do povoamento florestal e a Figura 5b apresenta a posição das medidas topográficas realizadas. As medidas realizadas no reflorestamento estão iluminadas na cor amarela, e em áreas de pasto na cor vermelha, utilizando a imagem obtida pelo radar na banda X como ilustração.

Fig. 5 - a) Levantamento topográfico; b) Levantamento topográfico na área de estudo.

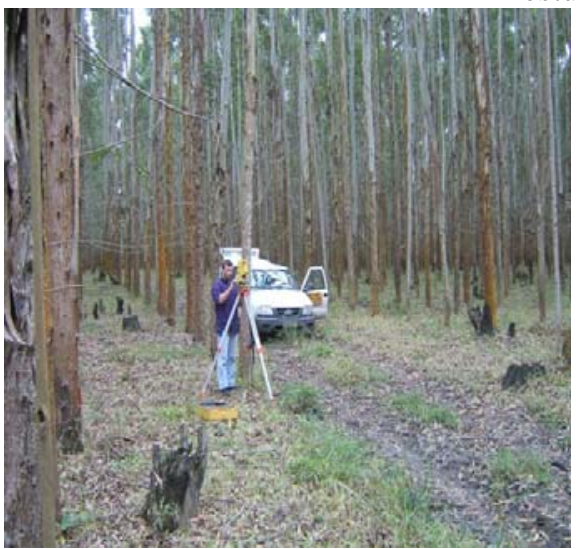

a)

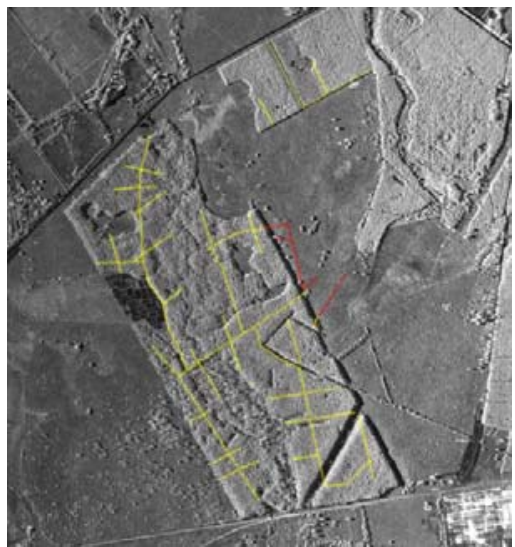

b)

\subsubsection{Geração dos dados}

Os dados de coerência interferométrica, do MDE, e das imagens no formato complexo na banda $\mathrm{P}$, foram obtidos nas quatro polarizações ( $\mathrm{HH}, \mathrm{VV}, \mathrm{HV}$ e VH), enquanto que os dados do radar na banda $\mathrm{X}$, como a coerência interferométrica, $\mathrm{O}$ MDE, e as imagens no formato complexo, foram obtidos apenas na polarização $\mathrm{HH}$.

Para a banda $\mathrm{X}$, empregou-se uma única passagem da aeronave para a aquisição dos dados interferométricos, uma vez que a baseline das antenas foi de 2 
metros, permitindo a utilização das 2 antenas simultaneamente na aeronave. Para a banda $\mathrm{P}$ foram necessárias duas passagens para a geração dos dados interferométricos, pois a baseline foi de aproximadamente 50 metros.

Para o processamento das imagens e dos produtos interferométricos (MDEs e coerências interferométricas) foi utilizado o software proprietário da Orbisat, para as análises dos produtos empregou-se o software ENVI-4.1, e para as análises estatísticas utilizou-se o programa Statistica-2.

\section{RESULTADOS}

\subsection{Modelo digital de elevação em área de pasto}

Os erros de planimetria não foram examinados, uma vez que durante o processo de geocodificação das linhas de vôo, o confronto das coordenadas dos pontos de registro GCPs (Ground Control Points) e dos correspondentes resultados obtidos, indicaram que a precisão planimétrica esteve muito acima das especificações da escala do mapeamento.

A comparação do MDE da banda X em áreas de pasto com o levantamento topográfico apresentou um comportamento linear com uma nuvem de dispersão em torno da reta de regressão, sem apresentar pontos muito afastados da nuvem. Quando comparados os valores das medidas topográficas com os valores do MDE na banda X, verificou-se um coeficiente de determinação $\left(R^{2}\right)$ de $93,81 \%$, indicando uma boa qualidade do MDE conforme se observa na Figura 6a.

Fig.6 - a) MDE na banda X versus Topografia; b) MDE da banda P versus Topografia.

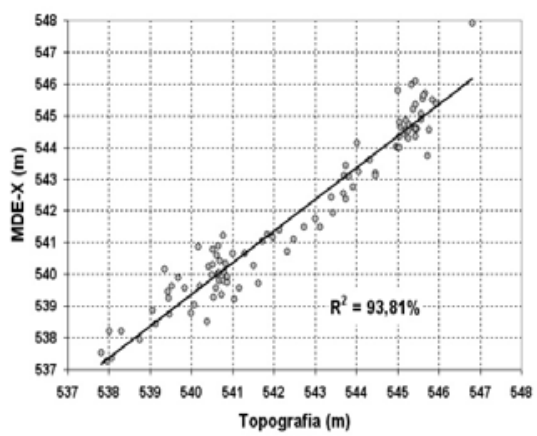

a)

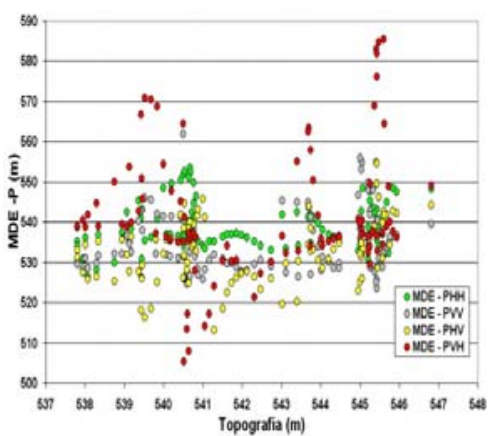

b)

Os MDEs obtidos na banda $\mathrm{P}$, nas quatro polarizações, apresentaram desvios padrão elevados, devido aos baixos valores da coerência interferométrica nas áreas de pasto, que era composta de gramíneas e de solo muito plano, com pouca rugosidade, que resultou em um espalhamento especular, causando baixo retorno, 
causando uma baixa coerência. A Figura 6b apresenta o comportamento do MDE na banda P com as medidas topográficas, onde se verifica um grande espalhamento dos pontos, com baixa correlação entre as variáveis.

Desta forma a melhor maneira de representação de áreas planas composta de pasto, ou de pouca vegetação, é a utilização do MDE na banda X. Atualmente a Orbisat gera MDEs cuja coerência interferométrica seja igual ou superior a 0,70 (70\%), como um fator de controle da qualidade do MDE.

\subsection{Modelo digital de elevação em área de Eucalyptus}

O MDE na banda $\mathrm{P}$, polarização $\mathrm{HH}$, apresentou similaridade em relação aos dados levantados pela topografia, indicando assim que o feixe do radar na banda $\mathrm{P}$ penetrou na floresta de Eucalyptus e interagindo com o solo dos talhões. Porém verificou-se que as polarizações apresentaram comportamentos diferentes em relação às medidas topográficas, conforme se observa na Figura 7.

Fig. 7 - MDE da banda P menos a altura topográfica.

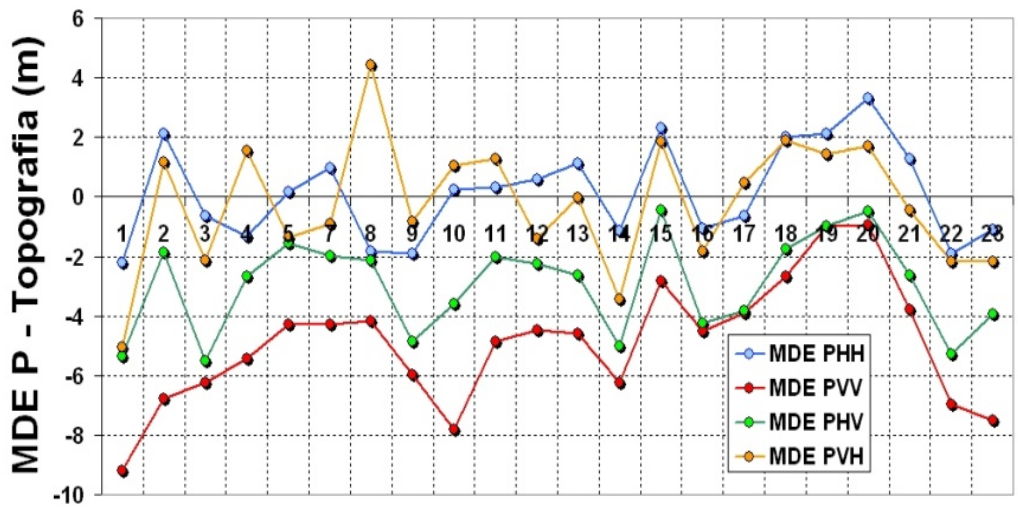

\section{Parcela}

Dentre as quatro polarizações utilizadas, a polarização $P_{H H}$ foi a que apresentou os menores valores de desvio padrão $(1,976 \mathrm{~m})$, e da diferença média $(0,007 \mathrm{~m})$, por interagir mais com o solo. Por sua vez, a polarização $\mathrm{P}_{\mathrm{Vv}}$ apresentou a diferença do valor médio mais elevado $(-5,295 \mathrm{~m})$ e um desvio padrão superior $(2,293 \mathrm{~m})$, provavelmente pelos efeitos de dupla rebatida (double-bounce) decorrente da vegetação ter como estrutura predominante os troncos, causando forte interação com os feixes verticais, prejudicando a penetração até o solo. A polarização $\mathrm{P}_{\mathrm{HV}}$ apresentou o seu desvio padrão $(1,991 \mathrm{~m})$ semelhante ao da polarização $P_{H H}$, mas a sua média das diferenças foi muito difenciada $(-2,938)$ conforme pode ser observado na Figura 7. Por sua vez, a polarização $\mathrm{P}_{\mathrm{VH}}$ apresentou um desvio padrão de 6,230m, com uma melhor resposta em relação à 
média das diferenças $(-0,193)$, indicando que o processamento interferométrico nas polarizações cruzadas merece estudos aprofundados uma vez que se esperava resultados semelhantes devido o princípio da reciprocidade.

A comparação do MDE na banda X com as medidas de campo indicou que não houve penetração significativa dos sinais de microondas no povoamento de Eucalyptus, uma vez que os valores médios da altura se apresentaram similares aos da altura da vegetação (altura das árvores adicionada à altura topográfica), conforme se observa na Figura 8.

Fig.8 - Resultado do mapeamento nas parcelas.

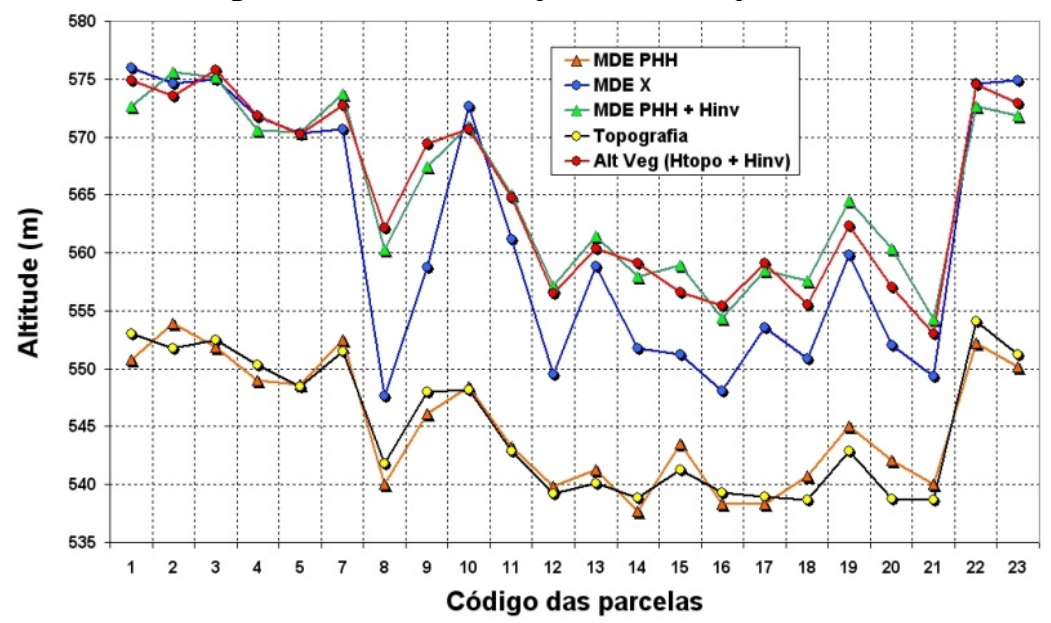

Comparando-se os valores altimétricos obtidos pelo MDE da banda X, com a altitude medida da altura da vegetação, através da composição das medidas topográficas das parcelas e as respectivas medidas da altura das árvores, verificouse um comportamento linear com similaridade em alguns casos, cujo coeficiente de determinação obtido foi de 90,33\%, , conforme se observa na Figura 9a.

Verifica-se na Figura 9a que alguns pontos se distanciaram da reta de regressão, e uma possível hipótese para este comportamento é a influência das falhas do povoamento com distribuição espacial variada no interior das parcelas. Estas descontinuidades, devido à ausência de indivíduos e/ou falhas no desenvolvimento da copa, que foram identificadas e medidas durante o inventário florestal, causam uma descontinuidade na superfície da copa do bioma, em que o MDE da banda X não conseguiria representar o solo nos casos de espaçamento pequenos, conforme ilustrado nas Figuras 9b e 9c. 
Fig.9 - a) MDE da banda X versus a altitude das parcelas; b) e c) Efeito das falhas no povoamento no MDE - X.

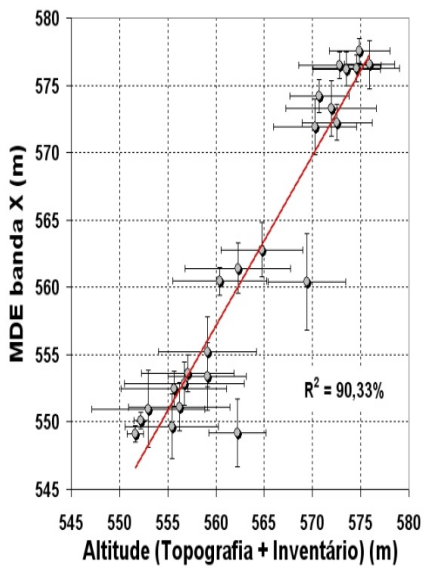

a)
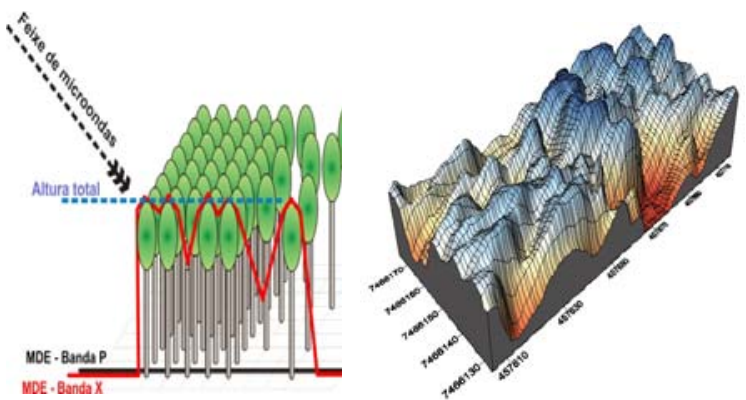

b) c)

Analisando os percentuais de falhas do povoamento, obtidas no inventário florestal com a diferença do MDE da banda X e a combinação das medidas de altura topográfica e do inventário para representar a altura das árvores, verificou-se uma tendência fraca entre as variáveis. Verifica-se uma grande nuvem de dispersão dos pontos até 35\% de falhas, e nos casos de maior percentual de falhas a diferença se mostrou significativa. Realizando uma regressão linear aos dados verificou-se um coeficiente de determinação de 14,72\%; conforme ilustrado no gráfico da Figura 10.

Fig.10 - Altura da vegetação versus falhas das parcelas.

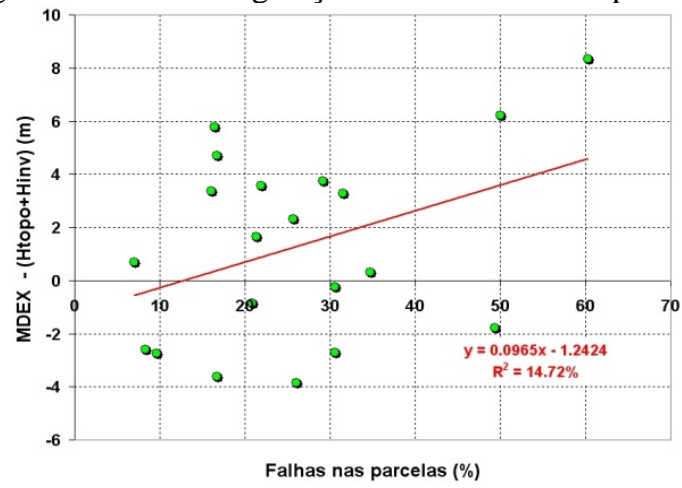

Comparando-se a coerência interferométrica da banda X com a variação Bol. Ciênc. Geod., sec. Artigos, Curitiba, v. 16, nº 4, p.519-537, out-dez, 2010. 
do MDE das copas nas parcelas na banda X, verificou-se uma relação de 18,19\% entre as variáveis. Observou-se uma correlação negativa entre as variáveis, em que menores variações da altura das árvores resultaram em valores de coerência mais altas; e nos casos de maiores valores de variação acarretaram em baixos valores de coerência (Figura 11a). Este comportamento é interessante por permitir uma análise da homogeneidade do dossel, face o provável crescimento regular do talhão de Eucalyptus.

Fig.11 - a) Coerência interferométrica com a variação do MDE-X; b) Coerência interferométrica pelo desvio padrão do inventário.

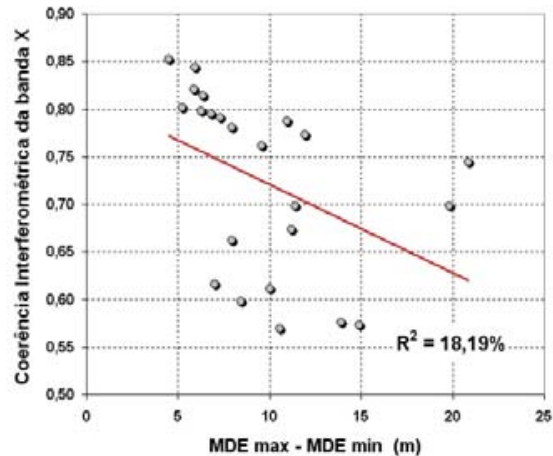

a)

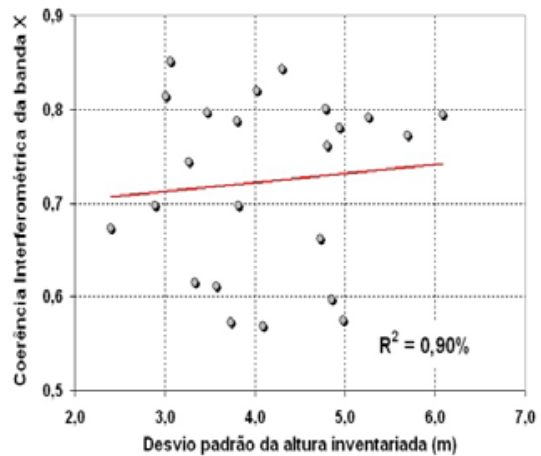

b)

Analisando o gráfico do espalhamento do desvio padrão do inventário da altura das árvores com a coerência interferométrica (Figura 11b), verificou-se uma grande dispersão dos dados, que representa uma baixa correlação entre elas (0,90\%), indicando para o caso em estudo, que a coerência interferométrica não conseguiu detectar as variações da altura da vegetação.

\subsection{Classes do mapeamento}

A avaliação da escala do mapemento altimétrico do terreno e da vegetação foi realizada por meio de uma análise das discrepâncias, utilizando-se o critério do Padrão de Exatidão Cartográfica - PEC (Lei 89817 de 1984, capítulo II, Seções I e II), em que a exatidão cartográfica é estabelecida pela análise de dispersão das diferenças. Para a classificação tipo "Classe A", 90\% dos pontos analisados não devem ultrapassar a metade da eqüidistância entre as curvas de nível, e um terço desta eqüidistância corresponderá ao erro padrão correspondente para pontos isolados.

Por este critério de análise de produtos cartográficos, verifica-se que a distribuição das discrepâncias entre o MDE e as medidas topográficas deve ter como limiar de fronteira, o ponto de $90 \%$ dos casos, correspondendo a 
1,6449*Desvio Padrão (DP), conforme ilustrado na Figura 12.

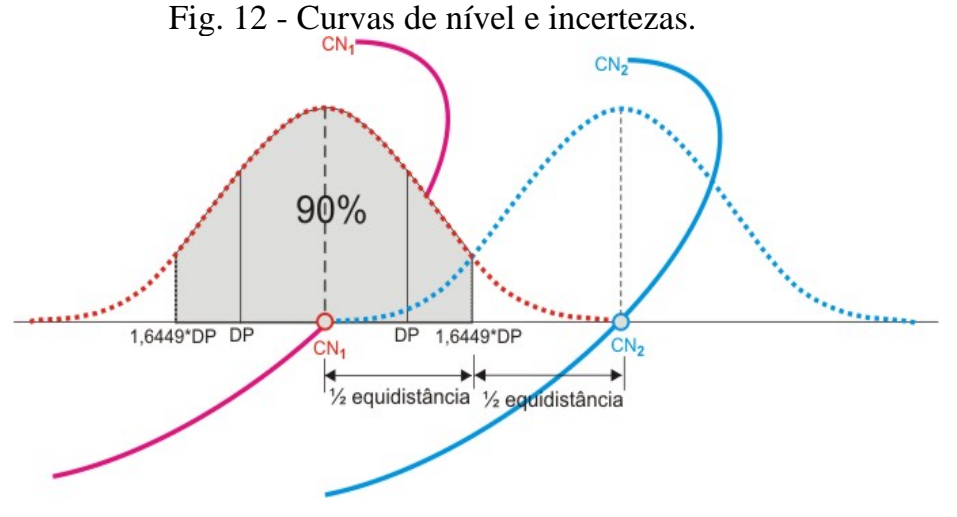

Este limite também ocorre na curva de nível seguinte $\left(\mathrm{CN}_{2}\right)$, obtendo-se assim a menor eqüidistância para a categoria de cartas classe A, i.e. a eqüidistância será o dobro do PEC correspondente. Para a avaliação da escala final se aplica a menor representação gráfica de $0,2 \mathrm{~mm}$, permitindo obter a escala do mapa. A Tabela 1 apresenta as distribuições das discrepâncias de duas curvas de nível subseqüentes $\left(\mathrm{CN}_{1}\right.$ e $\left.\mathrm{CN}_{2}\right)$ para a discriminação do terreno, onde o desvio padrão (DP) dos dados corresponde a $60,8 \%$ e o ponto limite de $90 \%$. Para classificar uma carta na classe B a distância entre do ponto limite corresponderá a três quintos da eqüidistância, e para a classe $\mathrm{C}$ corresponderá a três quartos do valor. Foi realizado um teste estatístico (teste $t$ ), para $5 \%$ de confiança, de forma a confrontar os dados altimétricos dos MDEs com os levantamentos topográficos. Nesta avaliação observou-se que para a área de pasto apenas o MDE obtido na banda X não foi tendencioso, enquanto que para a área de Eucalyptus o teste $t$ indicou que apenas o MDE na banda $\mathrm{P}$ polarização $\mathrm{HH}$, não foi tendencioso representando assim melhor a superfície.

Baseado nos resultados apresentados na Tabela 1 verifica-se que nas áreas de pasto o MDE na banda X apresentou a melhor exatidão cartográfica quando comparado com os MDEs na banda $\mathrm{P}$, que apresentaram escalas menores. Isto se deve ao fato da coerência interferométrica neste tipo de área ter sido alta na banda $\mathrm{X}$, significando uma maior acurácia do modelo. As coerências interferométricas na banda $\mathrm{P}$ apresentaram valores baixos, que resultam em uma menor qualidade do MDE. 
Tabela 1 - Classe de mapeamento.

\begin{tabular}{|c|c|c|c|c|c|c|}
\hline & & $\mathbf{X}_{\mathrm{HH}}$ & $\mathbf{P}_{\mathbf{H H}}$ & $\mathbf{P}_{\mathrm{VV}}$ & $\mathbf{P}_{\mathrm{HV}}$ & $\mathbf{P}_{\mathrm{VH}}$ \\
\hline \multirow{7}{*}{$\frac{8}{5}$} & $\begin{array}{l}\text { Média da dif. } \\
\text { (MDE-TOP) }\end{array}$ & $-0,665$ & $-3,450$ & $-7,519$ & $-9,395$ & $-4,452$ \\
\hline & $\begin{array}{l}\text { Teste } \\
\mathrm{t}_{(0,975 ; 106)}\end{array}$ & $\begin{array}{c}\text { Não } \\
\text { tenden- } \\
\text { cioso } \\
\end{array}$ & $\begin{array}{c}\text { Tenden- } \\
\text { cioso }\end{array}$ & $\begin{array}{c}\text { Tenden- } \\
\text { cioso }\end{array}$ & $\begin{array}{c}\text { Tenden- } \\
\text { cioso }\end{array}$ & $\begin{array}{c}\text { Tenden- } \\
\text { cioso }\end{array}$ \\
\hline & D.padrão (m) & 0,668 & 6,175 & 7,681 & 8,001 & 20,548 \\
\hline & PEC & 1,099 & 10,155 & 12,631 & 13,158 & 33,791 \\
\hline & $\begin{array}{ll}\text { Escala } & - \\
\text { Classe A } & \\
\end{array}$ & 7324 & 67699 & 84209 & 87718 & 225275 \\
\hline & $\begin{array}{ll}\text { Escala } & - \\
\text { Classe B } & \\
\end{array}$ & 3662 & 33849 & 42105 & 43859 & 112637 \\
\hline & $\begin{array}{ll}\text { Escala } & - \\
\text { Classe C } & \\
\end{array}$ & 2441 & 22566 & 28070 & 29239 & 75092 \\
\hline \multirow{7}{*}{ 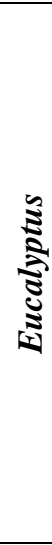 } & $\begin{array}{l}\text { Média da dif. } \\
\text { (MDE-TOP) }\end{array}$ & 14,449 & 0,007 & $-5,295$ & $-2,938$ & $-0,193$ \\
\hline & $\begin{array}{l}\text { Teste } \\
\mathrm{t}_{(0,975 ; 1220)}\end{array}$ & $\begin{array}{c}\text { Tenden- } \\
\text { cioso }\end{array}$ & $\begin{array}{c}\text { Não } \\
\text { tenden- } \\
\text { cioso } \\
\end{array}$ & $\begin{array}{c}\text { Tenden- } \\
\text { cioso }\end{array}$ & $\begin{array}{c}\text { Tenden- } \\
\text { cioso }\end{array}$ & $\begin{array}{c}\text { Tenden- } \\
\text { cioso }\end{array}$ \\
\hline & D.padrão (m) & 17,306 & 1,976 & 2,293 & 1,991 & 6,230 \\
\hline & PEC & 28,460 & 3,250 & 3,771 & 3,274 & 10,245 \\
\hline & $\begin{array}{l}\text { Escala } \\
\text { Classe A } \\
\end{array}$ & 189731 & 21664 & 25139 & 21828 & 68302 \\
\hline & $\begin{array}{ll}\text { Escala } & - \\
\text { Classe B } & \\
\end{array}$ & 94866 & 10832 & 12569 & 10914 & 34151 \\
\hline & $\begin{array}{ll}\text { Escala } & - \\
\text { Classe C } & \\
\end{array}$ & 63244 & 7221 & 8380 & 7276 & 22767 \\
\hline
\end{tabular}

Esta diferenciação de comportamento da coerência se deve a interação da onda eletromagnética com os alvos. A onda eletromagnética na banda $\mathrm{X}$ possui um comprimento de onda da ordem de $3 \mathrm{~cm}$, e desta forma o retroespalhamento foi significativo nas áreas de pasto; enquanto que o comprimento de onda da banda $\mathrm{P}$, da ordem de $72 \mathrm{~cm}$, apresentou um baixo retroespalhamento em áreas de pasto devido ao efeito especular de interação com o alvo.

Analisando o comportamento dos modelos obtidos nas áreas de Eucalyptus, verificou-se um comportamento oposto ao da área de pasto. Devido à baixa penetração da banda X, o MDE apresentou um valor de escala pior do que o da banda P para discriminar a altura do solo em áreas vegetadas. O MDE fornecido pela banda $\mathrm{P}$ forneceu uma maior escala de mapemento na polarização $\mathrm{HH}$, devido 
uma maior penetração do feixe de microondas na vegetação nesta polarização.

Por outro lado analisando o MDE da banda X como um discriminador da altura da vegetação, pode-se obter novas escalas de mapeamento, conforme apresentado na Tabela 2.

Tabela 2 - Escala de imageamento da banda X em área de Eucalyptus.

\begin{tabular}{c|c|c|c|c|c}
\hline $\begin{array}{c}\text { Média da } \\
\text { diferença } \\
\text { (MDE-TOP) }\end{array}$ & $\begin{array}{c}\text { Desvio } \\
\text { padrão } \\
(\mathrm{m})\end{array}$ & PEC & $\begin{array}{c}\text { Escala - } \\
\text { Classe A }\end{array}$ & $\begin{array}{c}\text { Escala - } \\
\text { Classe B }\end{array}$ & $\begin{array}{c}\text { Escala - } \\
\text { Classe C }\end{array}$ \\
\hline$-1,86$ & 2,721 & 4,475 & 29832 & 14916 & 9944 \\
\hline
\end{tabular}

A partir da análise dos resultados, verifica-se que o MDE da banda X apresenta uma melhor acuracia em discriminar a altura das árvores, mas apresentando uma classe de mapeamento inferior ao das áreas de pasto.

Com a finalidade de melhorar o resultado do MDE para discriminar a altura da vegetação foram empregadas técnicas estatísticas para desenvolver um modelo de regressão, através do critério Stepwise, do critério PRESS (soma de quadrados da predição) e dos testes de outliers e de homocedasticidade (Neter et. al., 1996).

Utilizando estas técnicas podem-se separar os dados obtidos pelo sensor SAR que mais se relacionavam com a altura da vegetação, de forma que as falhas das copas das árvores fossem compensadas.

Pelo Stepwise o modelo final para a altura das árvores pode ser verificado na equação 1 , onde a coerência interferométrica na banda $\mathrm{P}_{\mathrm{Vv}}$ (CohPvv) colaborou com o modelo com uma relação inversa, compensando as falhas do dossel. A variável LogHint corresponde ao logaritmo da altura interferométrica (Hint), que é a diferença do MDE na banda X e o MDE na banda $\mathrm{P}_{\mathrm{HH}}$.

$$
\text { Altura }=7,049+17,0131 * \log _{10} \text { Hint }-11,7418^{*} \text { CohPvv }
$$

Comparando o comportamento do modelo de regressão para o MDE das áreas de florestas de Eucalyptus com os dados topográficos associados aos do inventário florestal, verificou-se que o coeficiente de determinação melhorou (95,63\%) indicando uma melhor concordância com a média dos dados inventariais, conforme se observa no gráfico da Figura 19. 
Fig.19 - Modelo para MDE da vegetação versus a altitude das parcelas.

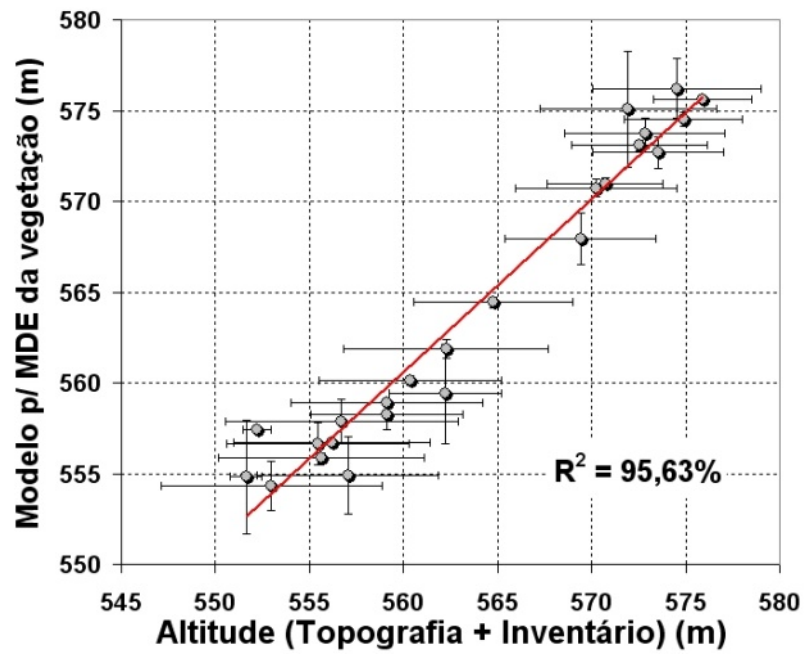

O valor do erro médio quadrático obtido na regressão foi de 0,9933, que representa em um erro de predição de $0,997 \mathrm{~m}$. Como a altura média das árvores do povoamento foi de $18,75 \mathrm{~m}$, o erro de predição correspondeu a 5,31 \%, e para a altura máxima de 23,31m o erro de predição correspondeu a 4,28 \%, valores aceitáveis para o limite de até $10 \%$ utilizado pelas empresas em suas estimativas.

Analisando a escala vertical obtida pelo modelo de regressão para discriminar a altura da vegetação, verificou-se uma ampliação da escala de mapeamento (1:15.528) quando comparado à escala de imageamento utilizando-se apenas o MDE na banda X (1:29.832). Desta forma a utilização da coerência interferométrica é um fator a ser considerado para melhorar os produtos cartográficos em áreas vegetadas, conforme se verifica na Tabela 3.

Tabela 3 - Escala de imageamento do modelo em área de Eucalyptus.

\begin{tabular}{c|c|c|c|c|c|c}
\hline $\begin{array}{l}\text { Média da Dif. } \\
(\mathrm{MDE}-\mathrm{TOP})\end{array}$ & $\begin{array}{c}\text { Desvio } \\
\text { padrão }(\mathrm{m})\end{array}$ & Teste $\mathrm{t}_{(0,975 ; 1220)}$ & PEC & $\begin{array}{c}\text { Escala } \\
\text { Classe } \\
\text { A }\end{array}$ & $\begin{array}{c}\text { Escala } \\
\text { Classe } \\
\text { B }\end{array}$ & $\begin{array}{c}\text { Escala } \\
\text { Classe } \\
\text { C }\end{array}$ \\
\hline 0,944 & 1,416 & Ñ-tendencioso & 2,329 & 15528 & 7764 & 5176 \\
\hline
\end{tabular}

Comparando os resultados das tabelas 2 e 3, a diferença da média do MDE utilizando o modelo de regressão diminuiu, indicando um melhor ajustamento com a verdade de campo. O teste $t$, para $5 \%$ de confiança, indicou que apenas o MDE obtido pela modelo de regressão não foi tendencioso. 


\section{CONCLUSÕES E CONSIDERAÇÕES FINAIS}

Os melhores modelos de elevação do solo em áreas de pasto foram os gerados na banda $X$, que apresentou uma escala de mapeamento compatível com a resolução empregada, enquanto que os modelos de elevação na banda $\mathrm{P}$ apresentaram valores elevados de desvio padrão, devido aos baixos valores de retroespalhamento que levaram a ter baixos valores de coerência interferométrica.

O melhor modelo de elevação do solo em áreas vegetadas por Eucalyptus foi obtido na banda $\mathrm{P}_{\mathrm{HH}}$, cujos valores de retroespalhamento foram superiores aos das áreas de pasto, fazendo com que a coerência interferométrica fosse superior, obtendo um modelo de elevação mais acurado. Este comportamento corrobora a hipótese da penetração do feixe radar da banda P em floresta, e particularmente a polarização $\mathrm{HH}$ sofreu menor distúrbio por interagir com os componentes horizontais da vegetação ao invés dos verticais, que é o predominante em Eucalyptus.

Por sua vez, o uso dos modelos de elevação para discriminar a altura das árvores utilizando apenas a banda $\mathrm{X}$, geraram produtos cartográficos abaixo da resolução altimétrica esperada. As falhas e aberturas das copas das árvores associadas à resolução do mapeamento afetaram a capacidade de representação da superfície do dossel. A utilização de modelos de regressão para determinar a altura da vegetação melhorou a qualidade do produto cartográfico final, uma vez que a coerência interferométrica compensou os erros de medida da altura.

De forma geral, os modelos de elevação por interferometria radar apresentaram grande potencial para inventários florestais de grandes áreas, por permitir uma visão sinótica da altura das árvores, e empregando equações alométricas podem-se obter os demais parâmetros da vegetação como biomassa, volume e DAP.

A hipótese de que ocorram maiores diferenças de altimetria em áreas de maior declividade do terreno não foi conclusiva pelas análises realizadas. Para este caso, necessita-se realizar mais testes em áreas que apresentem uma maior variação de declividade do terreno. Como ocorrerá uma maior variação do ângulo de incidência local em terrenos de maior declividade, o sinal de retorno do radar será influenciado, e novas abordagens deverão ser utilizadas para compensar este efeito.

No mapeamento da área de estudo foi utilizada a primeira versão do radar da Orbisat. Atualmente o sistema OrbiSAR encontra-se na sua terceira versão, com potencial para mapeamento superior a 1:25000 na banda $\mathrm{P}$, recomendando-se assim novos testes com o sistema atual.

\section{AGRADECIMENTOS}

Os autores agradecem o apoio da 5ํㅗㄹ Divisão do Serviço Geográfico do Exército Brasileiro, Nobrecel Celulose e Papel S.A., Diâmetro Biometria e Inventário Florestal, e a Orbisat Aerolevantamento S.A., pelo apoio prestado para a execução deste trabalho. 


\section{REFERÊNCIAS BIBLIOGRÁFICAS}

BORGEAUD M.; WEGMUELLER, U. On the use of ERS SAR Interferometry for Retrieval of Geo- and Bio - Physical Information, In: ESA Workshop on Applications of ERS SAR Interferometry - FRINGE/96, 1996, Zurich. Proceedings Zurich, 1996

GAMA, F. F.; SANTOS, J.R. ; MURA, J.C. ; RENNÓ, C. D. Estimation of biophysical parameters in the Eucalyptus stands by SAR data. Ambiência, Guarapuava/PR, v. 2, p. 29 - 42, 20 out. 2006.

GRAHAM, L. C. Synthetic interferometer radar for topographic mapping. Proceeding of the IEEE, v. 62, n. 6, p. 763-768, Jun. 1974.

KÖPPEN, W. Climatologia: con un estúdio de los climas de la tierra. Fondo de Cultura Econômica. México. p. 479, 1948.

MURA, J.C. Mapeamento topográfico por interferometria utilizando imagens SAR do ERS-1. In: Simpósio brasileiro de computação gráfica e processamento de imagens-SIBGRAPI, 6. 1993, Recife. Anais. Recife: SBC,UFPe, 1993. p.61-64.

NEEFF T., DUTRA L.V, SANTOS J.R., FREITAS C.C., ARAUJO L.S. Tropical forest measurement by interferometric height modeling and P-band backscatter. Forest Science. Bethesda, MD, USA, v. 51, n. 6, p. 585-594, 2005.

NETER, J., KUTNER M.H., NACHTSHEIM, C.J., WASSERMAN, W. Applied Linear Statistical Models, Boston, MA, McGraw-Hill, 1996.

MURA J.C., BINS L.S., GAMA F.F., FREITAS C.C., SANTOS J.R., DUTRA L.V. Identification of the Tropical Forest in Brazilian Amazon based on the MNT diference from $\mathrm{P}$ and $\mathrm{X}$ bands interferometric data. [CD-ROM] In: IGARSS - International Geoscience And Remote Sensing Symposium, Sidney, 2001 Proceedings. IEEE, Apr. 2001.

OLIVEIRA, J. B. DE; CAMARGO, M. N.; ROSSI, M.; CALDERANO FILHO, B. Mapa pedológico do Estado de São Paulo: legenda expandida. Campinas: Instituto Agronômico; Rio de Janeiro: Embrapa Solos, 1999. 64 p.

ZEBKER, H. A., VILLASENOR, J. Decorrelation in interferometric radar echoes, IEEE Transactions on Geoscience and Remote Sensing, v. 30, n. 5, p. 950-959, Sep 1992.

(Recebido em fevereiro de 2010. Aceito em setembro de 2010.) 